\title{
Os sujeitos tornaram-se perversos no capitalismo contemporâneo?'
}

\author{
Raul Albino Pacheco Filho
}

Adjetivada de várias maneiras, a noção de perversão tornou-se recurso comum para muitos autores explanarem teoricamente sobre aspectos da sociedade capitalista contemporânea. Perversão ordinária, perversão generalizada, perversão comum, perversão narcisista, perversão de transferência, perversão bipolar, perversão do laço social, montagem perversa e sociabilidade perversa são alguns dos termos na literatura psicanalítica, das ciências sociais, ou da mídia, articulados a temas como: ausência de limites, desaparecimento do sujeito do inconsciente, queda do simbólico, banalização das relações sexuais, declínio da função paterna, final das ideologias, eliminação do Outro na economia psíquica, escárnio pelos valores, crise das figuras de autoridade, debilidade do corpo social, empobrecimento subjetivo.

Seria teórica e conceitualmente legítimo supor que se trata de uma migração maciça de sujeitos para o que o pensamento freudiano-lacaniano formalizou como estrutura clínica perversa? A estrutura perversa seria um sintoma da sociedade capitalista?

Pretendo fundamentar uma resposta inequivocamente negativa a essas questões, apoiando-me na distinção entre as seguintes noções:

- a perversão estrutural do falante, de seu gozo e pulsão: “toda sexualidade humana é perversa, se acompanhamos bem o que Freud diz" (LACAN, 1975-76/2007, p. 149);

- a estrutura clínica perversa, como uma "escolha" do sujeito para lidar com a falta (castração) do Outro;

- um regime de gozo (estrutura de um discurso) não fundado sobre a renúncia ao gozo, mas sim sobre a rejeição da castração: "a mais-valia é a causa do desejo do qual uma economia faz seu princípio: o da produção insaciável da falta-de-gozar [manque-à-jouir]" (LACAN, 1970/2003, p. 434).

1 Uma versão condensada deste trabalho foi apresentada com o título "Há disseminação da perversão no capitalismo contemporâneo?" no XVII Encontro Nacional da Escola de Psicanálise do Campo Lacaniano EPFCL - Brasil 2016 ("Problemas cruciais para a Psicanálise na atualidade"), realizado em novembro de 2016, em São Paulo (SP). 


\section{A perversão estrutural do falante}

Sobre a perversão estrutural do falante, lembro que, em "Três ensaios sobre a teoria da sexualidade”, Freud (1905/1974) traz a concepção da perversão polimorfa da sexualidade infantil, já que esta se manifesta por meio das pulsões parciais. Mas não sem esclarecer que algo de perverso se estende também pela vida sexual do adulto: "a extraordinária difusão das perversões força-nos a supor que tampouco a predisposição às perversões é uma particularidade rara, mas deve, antes, fazer parte da constituição que passa por normal" (Ibid., p. 104). A normalidade seria, portanto, o fruto do recalcamento de certas pulsões parciais e componentes das disposições infantis, "bem como da subordinação dos demais à primazia das zonas genitais" (Ibid., p. 172). E as fantasias inconscientes dos neuróticos teriam conteúdo similar às ações dos perversos, levando à conclusão de que o essencial da diferença entre eles seria o recalque das inclinações perversas, nos neuróticos. "Portanto, os sintomas se formariam, em parte, às expensas da sexualidade anormal; a neurose é, por assim dizer, o negativo da perversão" (Ibid., p. 101).

Porém, seria apressado (e equivocado) pretender-se que Freud traçava fronteiras nítidas e estanques entre uma sexualidade, que seria dita normal; e outra, que seria entendida como perversa:

A experiência cotidiana mostrou que a maioria dessas transgressões, no mínimo as menos graves dentre elas, são um componente que raramente falta na vida sexual das pessoas sadias e que é por elas julgado como qualquer outra intimidade. Quando as circunstâncias são favoráveis, também as pessoas normais podem substituir durante um bom tempo o alvo sexual normal por uma dessas perversões, ou arranjar-lhes um lugar ao lado dele. Em nenhuma pessoa sadia falta algum acréscimo ao alvo sexual normal que se possa chamar de perverso, e essa universalidade basta, por si só, para mostrar quão imprópria é a utilização reprobatória da palavra perversão. Justamente no campo da vida sexual é que se tropeça com dificuldades peculiares e realmente insolúveis, quando se quer traçar uma fronteira nítida entre o que é mera variação dentro da amplitude do fisiológico e o que constitui sintomas patológicos (Ibid., p. 98).

Abordando os avanços trazidos por Lacan em relação a Freud, Soler (2009) fala do que seria uma acepção de "perversão generalizada" que não implicaria a ideia de uma época histórica em que todos estariam migrando para a estrutura clínica perversa. Não há acesso ao parceiro sexual senão pelas pulsões parciais, o que faz com que o gozo do ato sexual seja o mesmo do sintoma, sempre perverso, fragmentário e insuficiente: o que Lacan expressa com a máxima "não há relação sexual". 
A distinção nítida entre os sexos encontrada no nível biológico contrastaria radicalmente com "a ambiguidade que persiste quanto a tudo que se possa inscrever dessa relação no nível do significante”, o que tem, como consequência, que:

No nível do sujeito, não há reconhecimento como tal do macho pela fêmea nem da fêmea pelo macho. [...] A tal ponto que, se na teoria se produzem diversos pares de opostos, ativo/passivo, voyeur/visto etc., nunca é promovida como fundamental nenhuma oposição que designe o par macho/fêmea (LACAN, 1968-69/2008, p. 309).

O êxito do ato sexual produz o insucesso da relação sexual, e tornar-se um ser de linguagem implica uma perda de gozo e a subversão das dotações instintuais como motor do movimento da vida; esta passa a ser governada pelas pulsões (sempre parciais), pelo desejo, objeto e gozo (sempre falta-a-ser). Cito alguns versos de Chico Buarque, em Soneto:

Por que me descobriste no abandono

Com que tortura me arrancaste um beijo

Por que me incendiaste de desejo

Quando eu estava bem, morta de sono?

De que romance antigo me roubaste

Com que raio de luz me iluminaste

Por que não me deixaste adormecida

E me deixaste só, com que saída?

A sexualidade humana é um drama, e como no inconsciente o homem nada sabe da mulher e a mulher nada sabe do homem, "no falo, se resume o ponto de mito em que o sexual se torna paixão do significante" (LACAN, 1970/2003, p. 410). A "maldição sobre o sexo", afirmada em Televisão (LACAN, 1974/2003), mal/dicção, deriva-se de que o inconsciente não dispõe de dois significantes, um correspondente ao homem e outro à mulher, para dizer o sexual: apenas o significante fálico. Aí está a fonte de todos os desencontros e a origem de todas as confusões. Cito Barthes (1981):

Dis-cursus é, originalmente, a ação de correr para todo lado, são idas e vindas, 'démarches', 'intrigas'. O enamorado não para de correr, na sua cabeça, de empreender novas diligências e de intrigar contra si mesmo. Seu discurso só existe através de lufadas de linguagem, que lhe vêm no decorrer de circunstâncias ínfimas, aleatórias (p. 1). 
A linguagem é uma pele: esfrego minha linguagem no outro. É como se eu tivesse palavras ao invés de dedos, ou dedos na ponta das palavras. Minha linguagem treme de desejo (p. 64).

\section{A estrutura clínica perversa}

Em O fetichismo (1927/1974), Freud abandona o simplismo da fórmula da neurose como o negativo da perversão, apresenta o fetiche como paradigma da estrutura clínica da perversão e mostra que sua complexidade nada fica a dever à da construção da fantasia do neurótico. Ambos visam manter distância da castração, diferindo nas vias utilizadas.

Acompanhando essa pista freudiana, Lacan, no Seminário 7 (1959-60/2008) e em Kant com Sade (1963/1998), reitera que a diferença entre o neurótico e o perverso não se resolve por uma oposição simples entre presença e ausência da fantasia; mas aponta uma diferença entre ambos, com a conhecida formulação do giro de $90^{\circ}$ no esquema da fantasia.

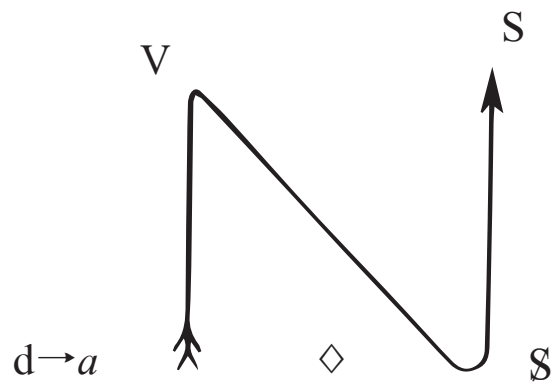

Figura 1: Esquema da fantasia do herói sadeano (fantasia do perverso)

Fonte: LACAN, J. (1963) Kant com Sade. In: Escritos. Rio de Janeiro: Jorge Zahar Ed., 1998, p. 786. 


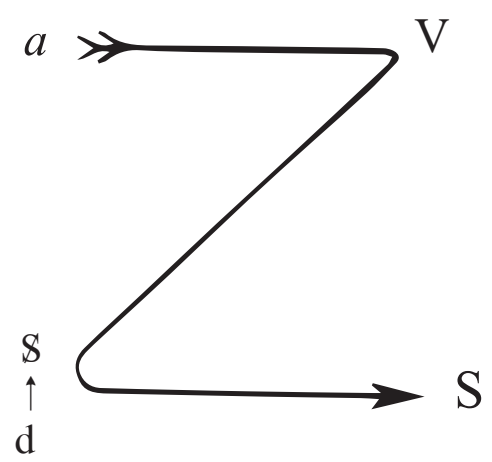

Figura 2: Esquema referente a Sade (fantasia do neurótico)

Fonte: LACAN, J. (1963) Kant com Sade. In: Escritos. Rio de Janeiro: Jorge Zahar Ed., 1998, p. 790.

Em sua tese Perversão: um fazer gozar (2011), Martinho esclarece essa diferença, mostrando que Lacan refuta a suposição de uma falsa simetria entre sádico e masoquista, que os alocaria em polos opostos: um como o que provoca e o outro como o que busca sofrimento. "A delegação que Sade faz a todos, em sua República, do direito ao gozo, não se traduz em nosso grafo por nenhuma reversão de simetria num eixo ou centro qualquer, mas apenas por uma rotação de um quarto de círculo" (LACAN, 1963/1998, p. 789). Lacan distingue o matema da fantasia do herói sadeano (protótipo da perversão) do matema que diz respeito à fantasia do próprio Sade, "porque na vida real Sade não era um sádico [...]. Lacan deixa transparecer a sua hipótese quanto à estrutura de Sade: em sua vida, Sade não era um perverso, mas um neurótico" (MARTINHO, 2011, p. 115).

No Seminário 16, Lacan (1968-69/2008) busca, para o real do gozo do falante, uma solução mais apropriada do que os empréstimos à termodinâmica, com que Freud tentou dar conta do "além do princípio do prazer". E teoriza a função mais-de-gozar do objeto a partir de uma homologia com a mais-valia de Marx. Isso lhe permite avançar ainda mais na formalização das estruturas e dos tipos clínicos, aí incluída a diferença entre o neurótico e o perverso. O perverso é aquele que zela pelo gozo do Outro e se consagra a tamponar seu buraco. Ou seja, como defensor da "fé", ele busca "a restituição do objeto a ao campo do A. [...] É a estrutura do sujeito para quem a referência da castração, isto é, o fato de a mulher se distinguir por não ter o falo, é tamponada, mascarada, preenchida pela operação misteriosa do objeto a" (Ibid., p. 283). Portanto, o fundamental na estrutura clínica perversa é a função de um "suplemento" que, no nível do Outro interrogue o que lhe falte e o ofereça. 
Já o neurótico não elude o que falta ao Outro no nível da própria lógica. O significado do A, como marcado por sua falha lógica, exprime-se completamente. Porém, carrega a nostalgia de uma suposta relação anterior de pseudocompletude com a mãe, em uma ilusão retroativa do paraíso perdido de um narcisismo primário que, de fato, nunca existiu. O que não impede sua busca incessante, tentando reencontrar "uma relação, não de suplemento, mas de complemento no Um". (Ibid., p. 252). Ele pretende ser o Um no campo do Outro.

\section{Uma estrutura discursiva sem barreira do gozo: o discurso capitalista}

Agora quero abordar o que acontece a partir da confluência do regime de gozo perverso estrutural do falante (aludido no item a), com o aparelhamento de gozo a que ele é submetido pelo discurso dominante em nossa época histórica: o discurso capitalista (assinalado no item c). Um discurso, que, ao mesmo tempo, sustenta e é sustentado por:

- uma estrutura particular das relações de produção (capitalistas);

- uma estrutura particular de relações de valor entre as coisas: a generalização da forma-mercadoria;

- $\quad$ suas consequências: a substituição da fetichização das relações entre os humanos falantes pela fetichização das relações entre os objetos mercadorias (ou latusas, como falava Lacan) e as transformações que isto implicou para a ordenação do gozo dos sujeitos.

Note-se que aqui estabeleço uma interlocução entre Marx e Lacan.

Repito aqui o que falei no IX Encontro Internacional dos Fóruns e da Escola de Psicanálise dos Fóruns do Campo Lacaniano (IF-EPFCL). ${ }^{2} \mathrm{~A}$ disseminação da forma-mercadoria cria o que Marx denominou fetichismo da mercadoria, que adere aos produtos do trabalho humano tão logo eles circulam como mercadorias: uma relação social entre humanos, que assume a forma fantasmagórica de uma relação entre coisas. Os produtos do trabalho humano parecem dotados de vida própria. Relacionam-se, uns com os outros, e com os humanos, como se fossem entidades cuja natureza essencial se fundamentaria somente nas conexões estabelecidas entre eles mesmos. Digamos que a forma-mercadoria "transforma a realidade social numa selva de espelhos, cada objeto contemplando especularmente, no outro, a es-

2 Apresentação "A teoria do valor e o laço 'associal' no capitalismo: homologias entre Marx e Lacan", no IX Encontro Internacional dos Fóruns e da Escola de Psicanálise dos Fóruns do Campo Lacaniano (IF-EPFCL), realizado em julho de 2016, em Medellín (Colômbia). 
sência abstrata de si mesmo" (EAGLETON, 1993, p. 270). Instaura-se uma lógica do mercado e uma hegemonia do consumo insaciável de mercadorias, em que, capturados em uma grande rede descentrada de desejo, "os indivíduos surgem como meros reflexos passageiros" (EAGLETON, 1998, pp. 127-128).

É isso que produz o que já se chamou de "laço associal" do discurso capitalista (BOUSSEYROUX, 2012).

Retomo algumas considerações sobre a mutação do regime de gozo, sob o capitalismo, que apresentei em um texto publicado em outro lugar (PACHECO FILHO, 2015). Há sempre uma "barreira do gozo" entre o lugar da produção e o lugar da verdade, nos discursos, como mostra Lacan no Seminário 17:

"Há aqui, com efeito, no andar inferior, uma barreira".

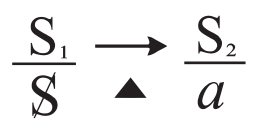

Figura 3

Fonte: LACAN, J. (1969-70) O seminário, livro 17: o avesso da psicanálise. Rio de Janeiro: Jorge Zahar Ed., 1992, p. 101.

A barreira cuja denominação está imediatamente ao alcance da nossa mão é, no nível do discurso do mestre, o gozo - na medida em que está interditado, interditado em seu fundo. Catam-se as migalhas de gozo [...] (LACAN, 1969-70/1992, p. 101).

A barreira do gozo também pode ser assinalada pelas setas dos matemas:

Discurso do Mestre

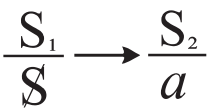

Discurso da Histérica

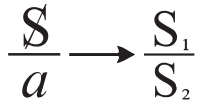

Discurso Universitário

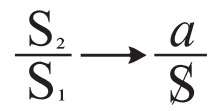

Discurso Analista

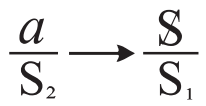

Figura 4: Os 4 discursos

Fonte: LACAN, J. (1972) Du discours psychanalytique. In: Lacan in Italia. Roma: Salamandra, 1984, p. 32. 
É sempre possível partir-se de qualquer um dos quatro "lugares" e, por meio das setas, fazer um percurso que chegue aos lugares correspondentes ao agente, ao outro e à produção: há sempre um circuito possível para esses lugares, por meio das setas. Mas nunca é possível chegar-se ao lugar da verdade, partindo-se de qualquer dos outros lugares.

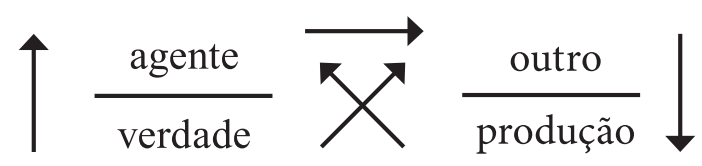

Figura 5: Lugares nos discursos

Fonte: PACHECO FILHO, R. A. Lugares nos discursos (Adaptação de Lacan), 2017.

Mas existe algo no discurso capitalista que o diferencia dos demais. Refiro-me à inexistência dessa "barreira do gozo", designada por Lacan como sendo a "impotência" necessária à estrutura de cada discurso.

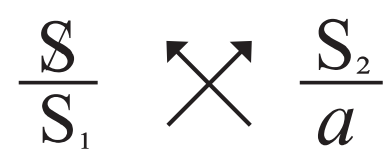

Figura 6: Discurso do Capitalista

Fonte: LACAN, J. (1972). Du discours psychanalytique. In: Lacan in Italia. Roma: Salamandra, 1984, p. 32.

Observe-se as setas dos matemas para notar que, no caso do discurso capitalista, o lugar da verdade tornou-se acessível, na medida em que, do lugar da produção, pode-se chegar ao lugar do agente pela seta diagonal que ascende inclinando-se para a esquerda. E daí é possível chegar-se ao lugar da verdade, pela seta vertical da esquerda, que desce até o lugar da verdade.

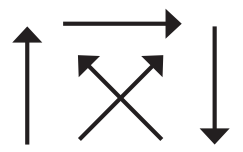

matema outros discursos

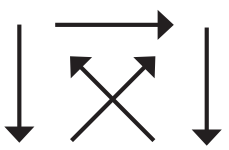

matema do discurso capitalista

Figura 7: Matemas com setas

Fonte: PACHECO FILHO, R. A. Matema do discurso capitalista, 2017. 
Lacan trata disso no Seminário 17, ao referir-se "ao que Marx demonstrou [...] no que se refere à produção, e que ele chama mais-valia, e não mais-de-gozar" (LACAN, 1969-70/1992, p. 169):

Alguma coisa mudou no discurso do mestre a partir de certo momento da história. Não vamos esquentar a cabeça para saber se foi por causa de Lutero, ou de Calvino, ou de não sei que tráfico de navios em torno de Gênova, ou no mar Mediterrâneo, ou alhures, pois o importante é que, a partir de certo dia, o mais-de-gozar se conta, se contabiliza, se totaliza. Aí começa o que se chama de acumulação de capital.

Vocês não sentem, em relação ao que enunciei há pouco sobre a impotência fazendo a junção entre o mais-de-gozar e a verdade do mestre, que aqui o passo ganha? [...] A mais-valia se junta ao capital - sem problemas, é homogêneo, estamos aí nos valores. Aliás, todos nós nadamos nisso no abençoado tempo em que vivemos.

O que há de chocante, e que não parece ser visto, é que a partir daquele momento o significante-mestre, por terem sido dissipadas as nuvens da impotência, aparece como mais inatacável, justamente na sua impossibilidade. Onde está ele? Como nomeá-lo? Como discerni-lo, a não ser, evidentemente, por seus efeitos mortíferos? Denunciar o imperialismo? Mas como pará-lo, esse mecanismo tão pequeno? (Ibid., p. 169).

O sujeito mergulhado no discurso capitalista, e mais propriamente, no que tem sido denominado "imperativo de gozo" da sociedade de consumo - consumo dos objetos que a ciência moderna permite fabricar -, permanece cativo das mercadorias, porque, na substituição metonímica frenética dos objetos colocados no lugar do mais-de-gozar, ele nunca se interroga sobre:

a fantasia de que a mercadoria possa dar conta absoluta (e sem falta) do seu desejo e gozo;

a origem da programação social que articula o objeto mais-de-gozar às mercadorias, domesticando sua pulsão nos limites da circunvolução incessante em torno das mesmas.

No avesso do discurso do analista, orientado pela experiência do inconsciente e do núcleo do real, nosso sujeito mergulhado no discurso capitalista é aquele que nada quer saber da experiência da castração e do impossível.

Lembra-nos Soler (2009) que o próprio exercício das pulsões parciais já inclui um efeito de castração (limitação do gozo), que não se deve ao Pai e à sua lei, mas apenas à perda da via original, da natureza e dos instintos: isso está incluído na perversão estrutural de todo falante. Ao incluírem a impotência e a castração, todos os discursos veiculam uma convocatória compatível com essa inacessibilidade estrutural da verdade e do gozo pleno. 
Todos, menos um: o discurso capitalista, que diz Lacan no seminário O saber do psicanalista (1971-72/inédito), distingue-se pela rejeição (Verwerfung). Rejeição para fora de todos os campos do simbólico: "rejeição de quê? Da castração". Devido a isso, esse discurso "deixa de lado o que chamaremos, simplesmente, as coisas do amor" (Ibid., Aula de 06/01/1972). Isso não transforma todos em perversos, nem viabiliza o gozo pleno, mas produz uma incoerência conflitiva entre: o regime de gozo acessível aos sujeitos, em função de sua condição estrutural de seres falantes (o "mal-estar na civilização");

a ordenação de gozo do capitalismo, pelo discurso nele dominante.

A isso podemos chamar, talvez, o "mal-estar no capitalismo". O que não recomenda uma nostalgia de volta ao passado e aos braços do amo antigo, já que, enquanto os caranguejos andam de lado, os reacionários engatam a marcha a ré e os assustados têm medo de sair do lugar, os interessados no progresso civilizatório têm muita curiosidade pelo que poderia ser encontrado adiante!

\section{Referências bibliográficas}

BARTHES, R. Fragmentos de um discurso amoroso. Rio de Janeiro: Francisco Alves, 2. ed., 1981.

BOUSSEYROUX, M. Práticas do impossível e teoria dos discursos. A Peste: Revista de Psicanálise e Sociedade, São Paulo, v. 4, n. 1/2, jan./jun./jul./dez. 2012, pp. 183-194.

EAGLETON, T. A ideologia da estética. Rio de Janeiro: Jorge Zahar Ed., 1993.

. As ilusões do pós-modernismo. Rio de Janeiro: Jorge Zahar Ed., 1998.

FREUD, S. (1905) Três ensaios sobre a teoria da sexualidade. In: Edição Standard Brasileira das Obras Psicológicas Completas. Rio de Janeiro: Imago, 1974, v. 7. (1906) Minhas teses sobre o papel da sexualidade na etiologia das neuroses. In: Edição Standard Brasileira das Obras Psicológicas Completas. Rio de Janeiro: Imago, 1974, v. 7.

(1927) O fetichismo. In: Edição Standard Brasileira das Obras Psicológicas Completas. Rio de Janeiro: Imago, 1974, v. 21.

LACAN, J. (1959-60). O seminário, livro 7: a ética da psicanálise. Rio de Janeiro: Jorge Zahar Ed., 2008.

. (1963) Kant com Sade. In: Escritos. Rio de Janeiro: Jorge Zahar Ed., 1998. . (1968-69) O seminário, livro 16: de um Outro ao outro. Rio de Janeiro: Jorge Zahar Ed., 2008.

- (1969-70) O seminário, livro 17: o avesso da psicanálise. Rio de Janeiro: Jorge Zahar Ed., 1992.

(1970) Radiofonia. In: Outros escritos. Rio de Janeiro: Jorge Zahar Ed., 2003. 
. (1971-72) O saber do psicanalista. Disponível em:

http://lacanempdf.blogspot.com.br/2016/09/livros-de-lacan_19.html. Acesso em: 13 maio 2017. Inédito.

. (1974) Televisão. In: Outros escritos. Rio de Janeiro: Jorge Zahar Ed., 2003

(1975-76) O seminário, livro 23: o sinthoma. Rio de Janeiro, Jorge Zahar Ed., 2007.

MARTINHO, M. H. C. Perversão: um fazer gozar. Tese (Doutorado em Psicanálise) - Instituto de Psicologia, Universidade do Estado do Rio de Janeiro, Rio de Janeiro, 2011.

PACHECO FILHO, R. A. Compra um Mercedes Benz pra mim? Psicologia Revista, São Paulo, v. 24, n. 1, 2015. pp. 15-44.

Do mel ao fel: metamorfoses da estratégia de gozo em Roman Polanski. Stylus: Revista de Psicanálise, Rio de Janeiro, n. 32, jun. 2016, 2010, pp. 163-177.

SOLER, C. (2009) La perversion généralisée. La clinique lacanienne, v. 16, n. 2. pp.117-131. Disponível em: www.cairn.info/revue-la-clinique-lacanienne-2009-2-page-117.htm. Acesso em: 13 maio 2017.

\section{Os sujeitos tornaram-se perversos no capitalismo contemporâneo? Have subjects become perverse in contemporary capitalism?}

\section{resumo}

Adjetivada de diversas maneiras, a noção psicanalítica de perversão tornou-se um recurso comum utilizado por diferentes autores para se referir e para explanar teoricamente a respeito de aspectos observados na sociedade capitalista contemporânea. Este artigo questiona se seria teoricamente razoável e conceitualmente legítimo supor que se trata de uma migração maciça de sujeitos para aquilo que o pensamento freudiano e lacaniano formalizou como sendo a estrutura clínica perversa. A perversão seria um sintoma da sociedade capitalista? A resposta negativa a esta questão apoia-se na distinção entre: a) a noção de uma perversão estrutural do falante, de seu gozo e da pulsão: "toda sexualidade humana é perversa"; b) a noção de estrutura clínica perversa, como uma "escolha" do sujeito para lidar com a falta (castração) do Outro; e c) a noção de um regime de gozo (um discurso) não fundado sobre a renúncia ao gozo.

\section{palavras-chave:}

Psicanálise; perversão; discurso capitalista; mais-de-gozar. 


\section{abstract}

Addressed in various ways, the psychoanalytic notion of perversion has become a common resource used by different authors to refer to and explain theoretically the aspects observed in the contemporary capitalist society. This article questions whether it would be theoretically reasonable and conceptually legitimate to assume that it is a massive migration of subjects to what the Freudian and Lacanian thought has formalized as the perverse clinical structure. Could perversion be a symptom of the capitalist society? The negative answer to this question is based on the distinction among: a) the notion of a structural perversion of the speaker, of their enjoyment and drive: "all human sexuality is perverse"; b) the notion of the perverse clinical structure as a "choice" of the subject to deal with the lack (castration) of the Other; and c) the notion of a regime of enjoyment (a discourse) not founded on the renunciation of enjoyment.

\section{keywords:}

Psychoanalysis; perversion; capitalist discourse; surplus-jouissance.

\section{Recebido:}

17/05/2017

\section{Aprovado:}

12/06/2017 